\title{
Landslide susceptibility mapping using certainty factor, index of entropy and logistic regression models in GIS and their comparison at Mugling-Narayanghat road section in Nepal Himalaya.
}

\begin{abstract}
Landslide susceptibility maps are vital for disaster management and for planning development activities in the mountainous country like Nepal. In the present study, landslide susceptibility assessment of Mugling-Narayanghat road and its surrounding area is made using bivariate (certainty factor and index of entropy) and multivariate (logistic regression) models. At first, a landslide inventory map was prepared using earlier reports and aerial photographs as well as by carrying out field survey. As a result, 321 landslides were mapped and out of which 241 (75\%) were randomly selected for building landslide susceptibility models, while the remaining $80(25 \%)$ were used for validating the models. The effectiveness of landslide susceptibility assessment using GIS and statistics is based on appropriate selection of the factors which play a dominant role in slope stability. In this case study, the following landslide conditioning factors were evaluated: slope gradient; slope aspect; altitude; plan curvature; lithology; land use; distance from faults, rivers and roads; topographic wetness index; stream power index; and sediment transport index. These factors were prepared from topographic map, drainage map, road map, and the geological map. Finally, the validation of landslide susceptibility map was carried out using receiver operating characteristic (ROC) curves. The ROC plot estimation results showed that the susceptibility map using index of entropy model with AUC value of 0.9016 has highest prediction accuracy of $90.16 \%$. Similarly, the susceptibility maps produced using logistic regression model and certainty factor model showed 86.29 and $83.57 \%$ of prediction accuracy, respectively. Furthermore, the ROC plot showed that the success rate of all the three models performed more than $80 \%$ accuracy (i.e. $89.15 \%$ for IOE model, $89.10 \%$ for LR model and $87.21 \%$ for $\mathrm{CF}$ model). Hence, it is concluded that all the models employed in this study showed reasonably good accuracy in predicting the landslide susceptibility of Mugling-Narayanghat road section. These landslide susceptibility maps can be used for preliminary land use planning and hazard mitigation purpose.
\end{abstract}

Keyword: Landslides; Susceptibility; Index of entropy; Certainty factor; Logistic regression; Geographic information systems (GIS); Remote sensing Nepal 